\title{
Patient Selection For Acute Stroke Intravenous Thrombolysis
}

\author{
Mehdi Farhoudi,. \\ Professor of Neurology, Neurosciences Research Center, Tabriz University of Medical Sciences, Tabriz, Iran. \\ *Corresponding Author: Email: farhoudi_m@yahoo.com
}

\begin{abstract}
Stroke is a leading cause of mortality worldwide. Unfortunately its incidence is more and the age of occurrence is one decade earlier in our country, Iran. About 75-90 percent of stroke etiology is ischemic. The only approved drug treatment for eligible acute ischemic stroke (AIS) patients is thrombolytic therapy by recombinant tissue plasminogen activator (tPA). Related level of evidence is the highest ( $1 \mathrm{a}$ ) and it has been approved by FDA following NINDS study since 1996. First golden time for use of tPA was less than 3 hours but later it has extended to 4.5 hours following re-analysis of the data since 2009. In the beginning, related exclusion criteria was strict considering many absolute items, however, some of them changed or removed as relative exclusion criteria by practicing and performing researches and analysis of results and it is going to be more simplified. For example, in 2013 there were 15 absolute and 10 relative exclusion criteria for intravenous thrombolysis in AIS in less than 4.5 hours period from onset of symptoms but in 2016 following publishing American heart and Stroke Association (AHA/ASA) scientific statement this criteria was more clarified and some of relative exclusion criteria removed. And finally new published researches extended this therapeutic time window to 6 hours by using mechanical thrombectomy in defined patients not responding to IV thrombolysis. In the ninth national Iranian Stroke Congress this updated criteria will be discussed.
\end{abstract}

Key words: Stroke, Intravenous Thrombolysis

DOI: $10.7575 /$ aiac.abcmed.ca1.50

Published Date: February 2017

Peer-review is under responsibility of the 9th Iranian Stroke Congress.

Published by Australian International Academic Centre, Australia

This published work is open access under the CC BY license.

Available online at www.abcmed.aiac.org.au 